BNL-113994-2017

\title{
Cadmium Zinc Telluride Selenide (CdZnTeSe) A Promising Low Cost Alternative to Cadmium Zinc Telluride (CdZnTe) for Medical Imaging and Nuclear Detector Applications
}

\author{
U. Roy, G. Camarda, Y. Cui, R. Gul, A. Hossain, G. Yang \\ Presented at the Greater NY Chapter of Health Physics Society Spring \\ Symposium \\ New York, $N Y$ \\ June 6, 2017
}

Nonproliferation and National Security Department

Radiation Detector and Nonproliferation R\&D Group

Brookhaven National Laboratory

\section{U.S. Department of Energy \\ USDOE National Nuclear Security Administration (NNSA), Office of Nonproliferation and Verification Research and Development (NA-22)}

Notice: This manuscript has been authored by employees of Brookhaven Science Associates, LLC under Contract No. DE- SC0012704 with the U.S. Department of Energy. The publisher by accepting the manuscript for publication acknowledges that the United States Government retains a non-exclusive, paid-up, irrevocable, world-wide license to publish or reproduce the published form of this manuscript, or allow others to do so, for United States Government purposes. 


\section{DISCLAIMER}

This report was prepared as an account of work sponsored by an agency of the United States Government. Neither the United States Government nor any agency thereof, nor any of their employees, nor any of their contractors, subcontractors, or their employees, makes any warranty, express or implied, or assumes any legal liability or responsibility for the accuracy, completeness, or any third party's use or the results of such use of any information, apparatus, product, or process disclosed, or represents that its use would not infringe privately owned rights. Reference herein to any specific commercial product, process, or service by trade name, trademark, manufacturer, or otherwise, does not necessarily constitute or imply its endorsement, recommendation, or favoring by the United States Government or any agency thereof or its contractors or subcontractors. The views and opinions of authors expressed herein do not necessarily state or reflect those of the United States Government or any agency thereof. 


\section{Cadmium Zinc Telluride Selenide (CdZnTeSe)}

A promising low cost alternative to Cadmium Zinc Telluride (CdZnTe) for medical imaging and nuclear detector applications

U. NRoy, G.S. Camarda, Y. Cui, R. Gul, A. Hossain, G. Yang

Brookhaven National Laboratory

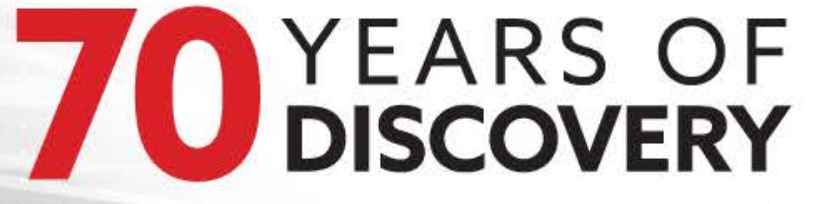

A CENTURY OF SERVICE

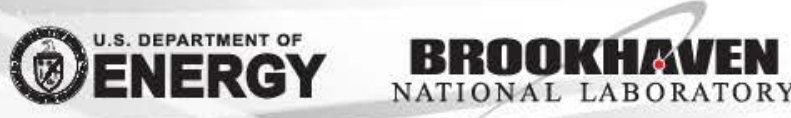




\section{Outline}

$\square$ Room temperature semiconductor radiation detector

$\square$ State of the art CdZnTe detectors and its disadvantages

$\square$ New development of CdZnTeSe material

Examples of medical applications 


\section{Scintillator vs semiconductor detectors}

\section{Indirect}

Conversion of Gammas to Electrons

Spread of light reduces spatial resolution

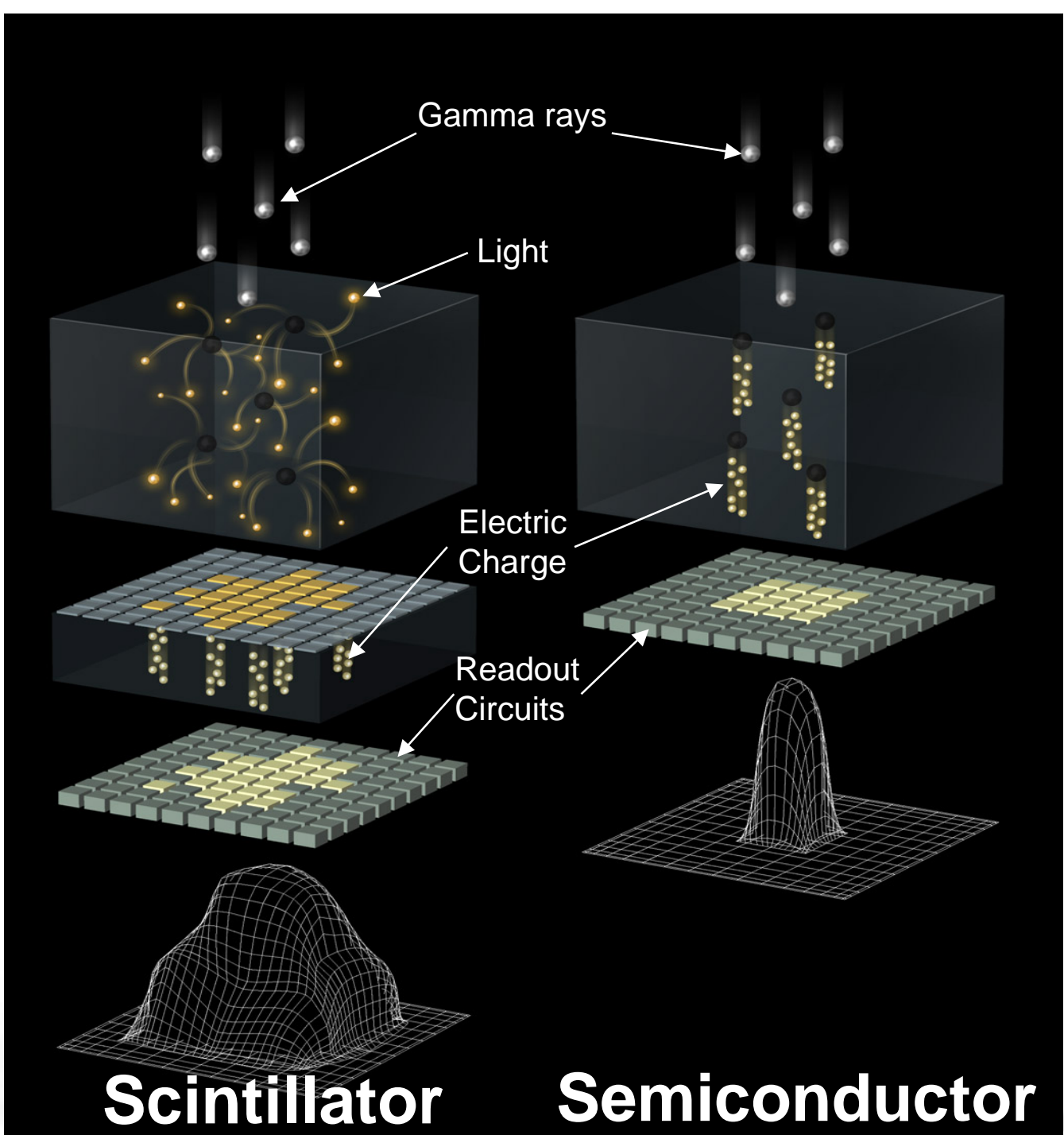

\section{Direct}

Conversion of Gammas to Electrons

Compactness of electric charge enhances spatial resolution 


\section{Generations of radiation detectors}

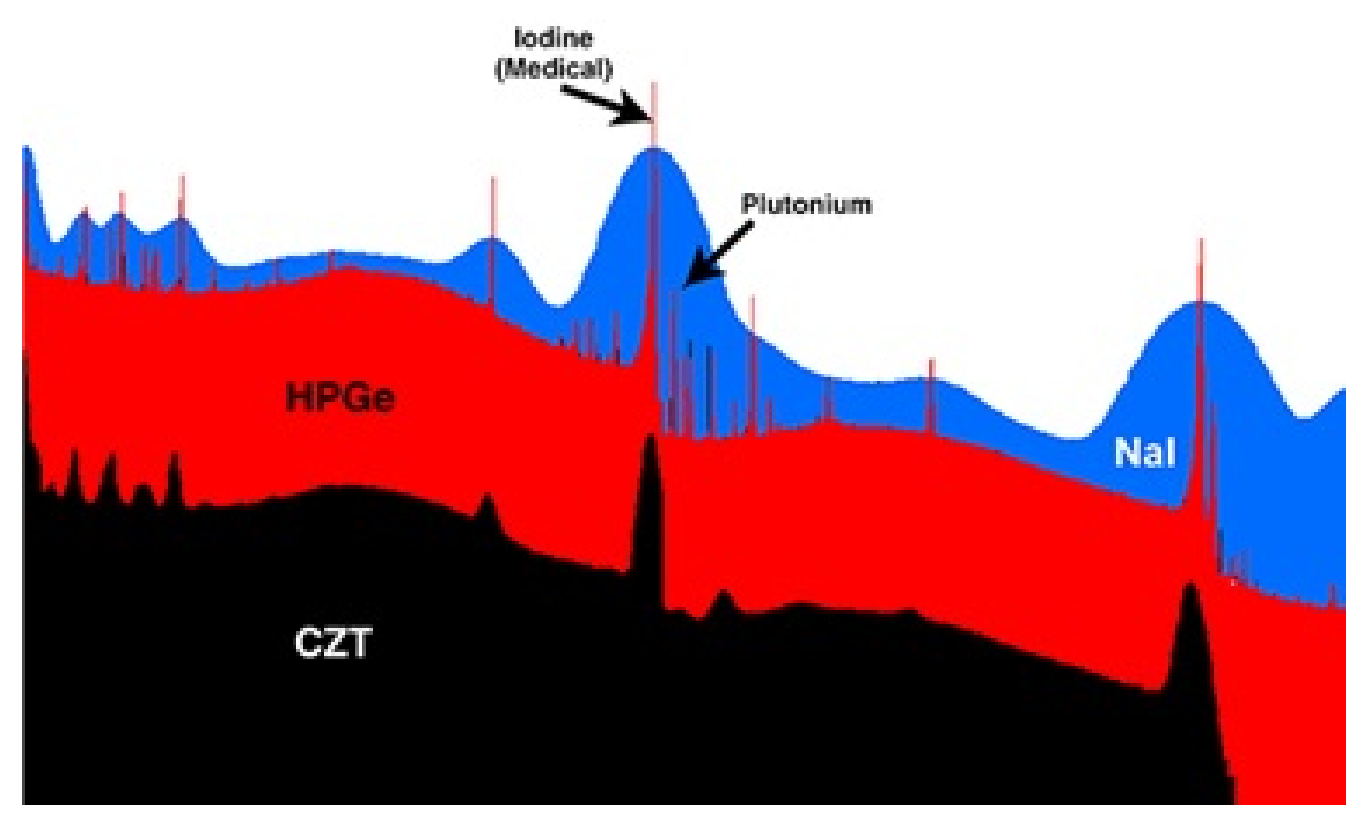

Comparison of Nal, HPGe and CZT Detectors (Courtesy of Ortec)

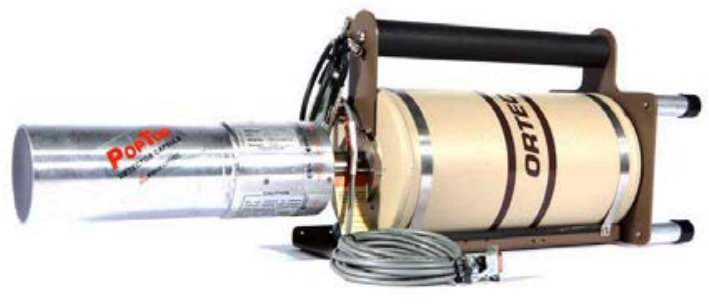

- Ge - High energy resolution, cryogenic cooling ( 0.3\% at 662 keV)

- NaI Scintillators - Low energy resolution.

- CZT based hand held detector, fairly high energy resolution ( 1\% resolution at $662 \mathrm{keV}$ ) 


\section{State-of-the-art: CdZnTe}

$\square$ Today, cadmium zinc telluride (CZT) is the most advanced roomtemperature semiconductor material for gamma-ray detection.

$\square$ However, CZT suffers from 3 major detrimental defects

- Non-unity segregation of $\mathbf{Z n}$

- Crystal defect (sub-grain boundary) network

- High concentrations of Te inclusions/precipitates
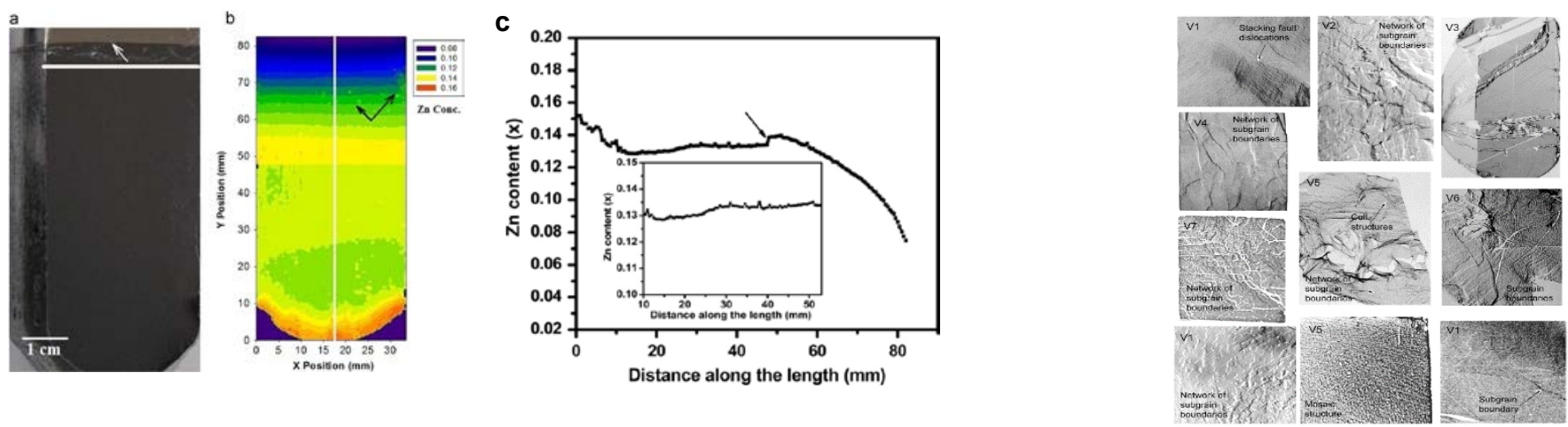

(a) THM-grown CZT ingot cut along the length, (b) Zn concentration mapping and (c) Zn concentration along the length of the ingot. Roy et al. J. Crystal Growth 347 (2012) 53.

$X$-Ray diffraction topography images showing $\sim 1 \mathrm{~cm}^{2}$ areas of detector-grade CZT samples supplied by seven different vendors. A. E. Bolotnikov et al. J. Cryst. Growth 379 (2013) 46.

- These issues cause low yield and high cost of CZT radiation detectors, limiting their applications.

- Researchers have tried to solve the issues by improving the crystal growth process and post-growth annealing, but have not mitigated all disadvantages. 


\section{Characterization Technique: X-ray Response Maps}

Micro-scale X-ray Detector Response Mapping is a unique and powerful measurement technique to evaluate detector performance.

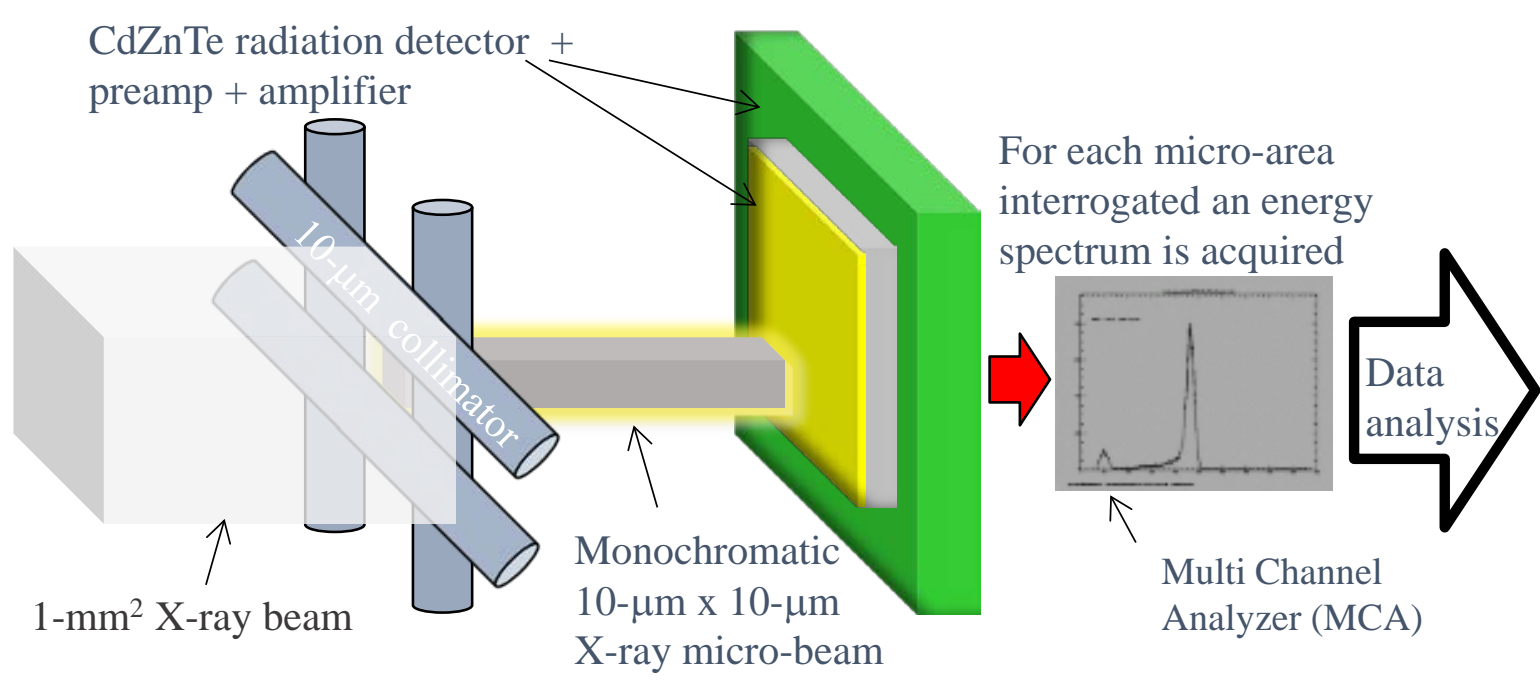

X-ray response maps can give information on:

1. Detector polarization

2. Local and global E-field non-uniformity

3. Extended defects

4. Electrode- and side-surfaces fabrication damage

5. Electrodes design

6. Non-uniformity of material

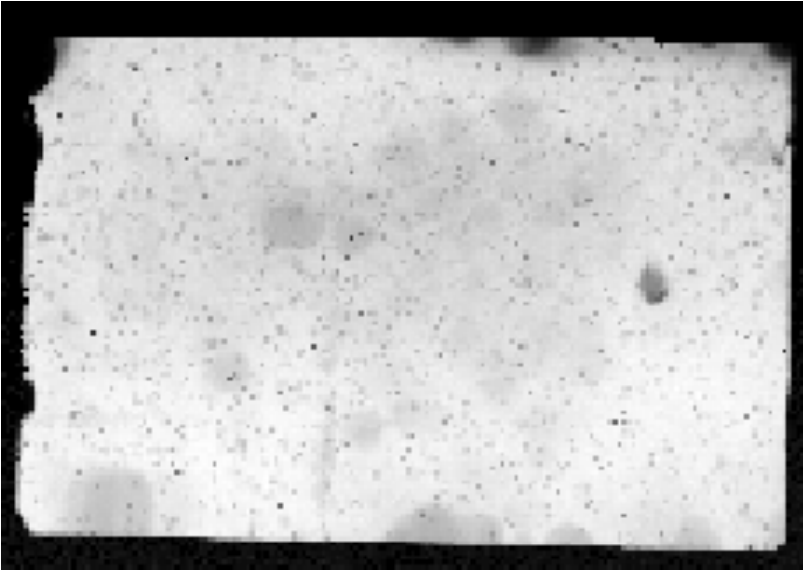

2D X-ray response map of a $16 \times 11 \times 2 \mathrm{~mm}^{3} \mathrm{CZT}$ detector 


\section{Effect of sub-grain boundary
network on device response}

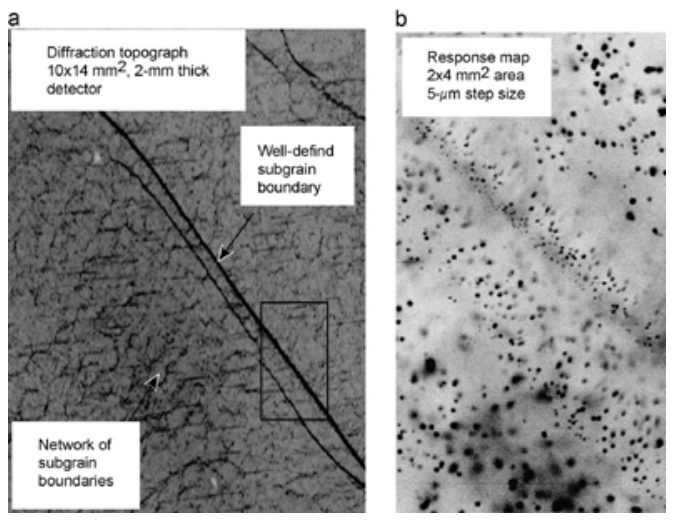

$X$-ray topography and the high-resolution $\mathrm{X}$-ray response map

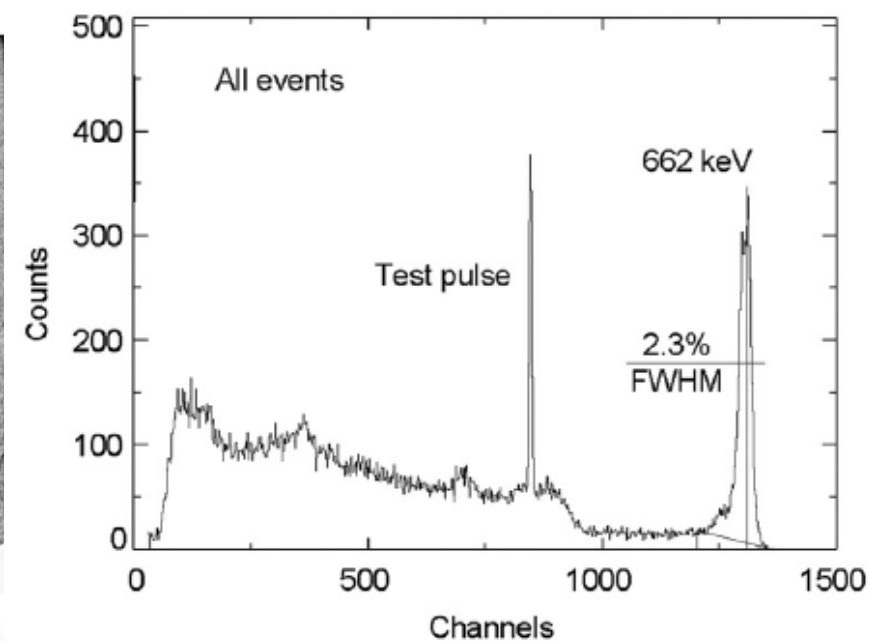

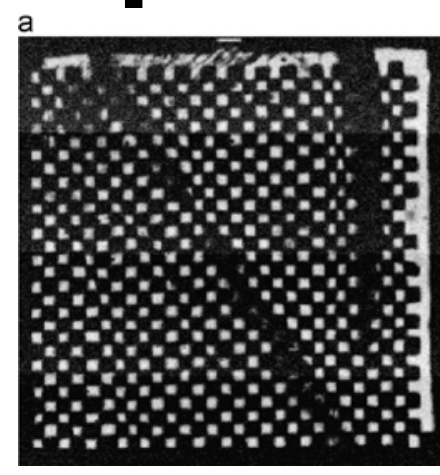

$\mathrm{X}$-ray topography and the high-resolution $\mathrm{X}$-ray response map of pixelated device (sample dimensions: 20x20x2 mm³
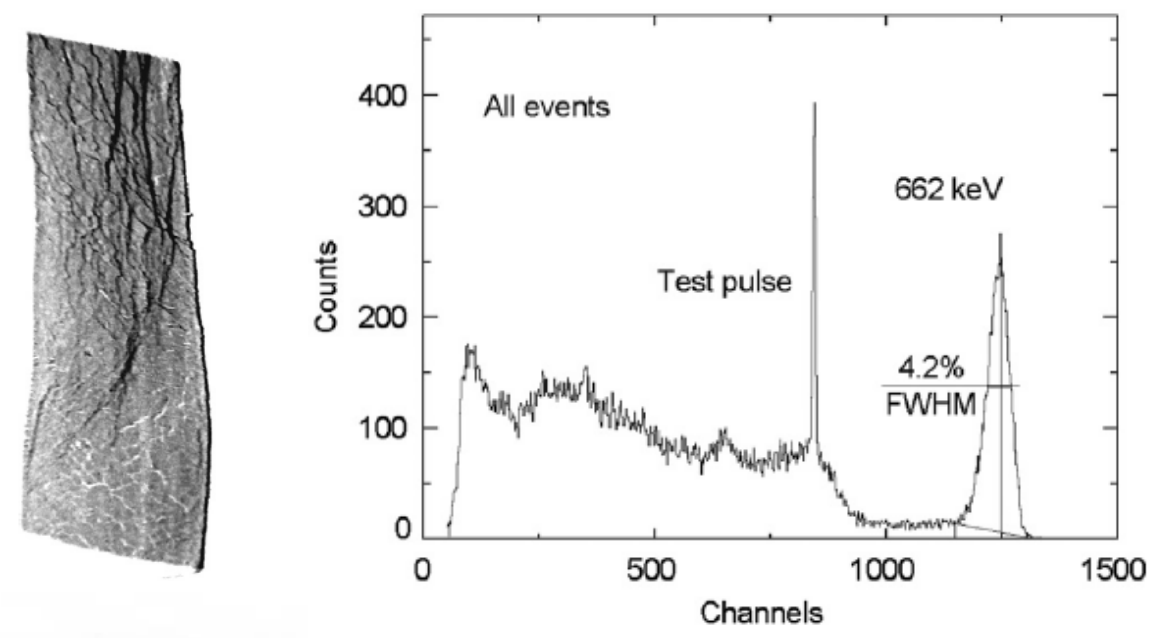

X-ray topography and the pulse height spectrum of Frisch-grid detector. Sample dimensions: 6x6x15 mm ${ }^{3}$. 


\section{Effect of Te-inclusions/precipitates on device response}

FWHM (\%) at $662 \mathrm{keV}$, of the cumulative effect of Te inclusions to energy resolution (after bi-parametric correction) versus their concentration calculated for 1-, 3-, 5-, 10-, and 20- $\mu \mathrm{m}$ inclusions. The detector's length is $\mathbf{1 5} \mathbf{~ m m}$.

A. E. Bolotnikov et al., IEEE Trans. on Nucl. Science 54, 821 (2007).
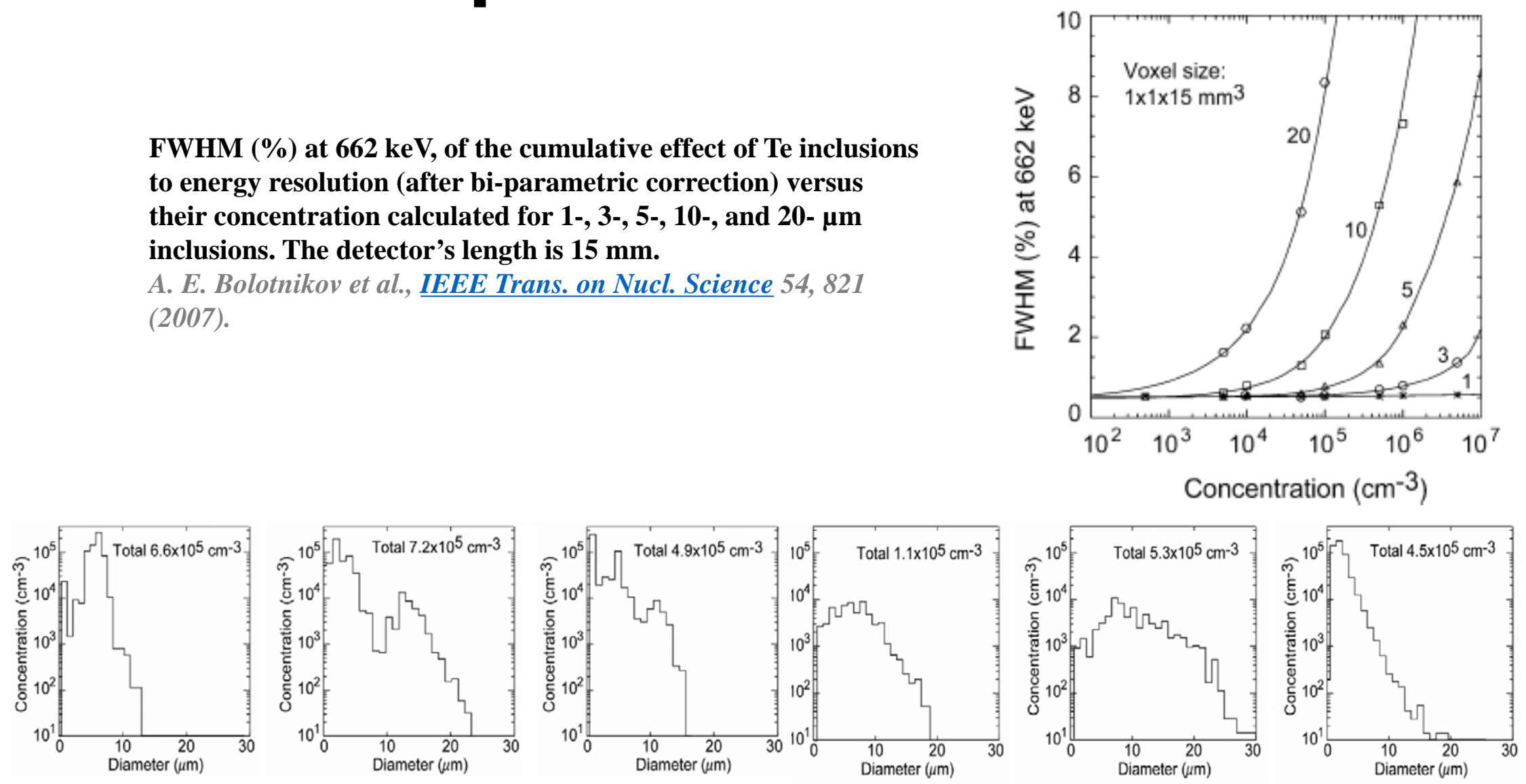

Size distribution and concentration of secondary phases for standard CZT from different vendors.

A. E. Bolotnikov et al., IEEE Trans. on Nucl. Science 57 (2010) 910. 


\section{Is it possible to develop new material to address the problems associated with today's CZT and at low cost?}

From our past experience Se was found to be very effective in reducing sub-grain boundary networks and Te inclusions/precipitates. In addition, the Se segregation coefficient is near unity in the CdTe matrix.

The proposed new quaternary semiconductor $C d_{1-x} Z n_{x} T e_{1-y} S e_{y}(C Z T S)$ is expected to resolve these long-standing problems associated with CZT material. Hence, high-performance detector-grade CZTS material can be potentially produced at lower cost. 


\section{Roles of Se}

- Strong influence in modifying Zn segregation coefficient: better compositional homogeneity with increased Se concentration.

- Effective solution hardening in arresting sub-grain boundaries and their network with increased Se content.

- Decreased Te-inclusion/precipitate concentration with increased Se content. 


\section{Growth and characterization}

$\square$ CZTS ingots were grown by traveling heater method (THM) as well as vertical Bridgman Method (BM).

- 6N purity CdZnTe and CdSe were used for synthesis of the CZTS compound.

- 6N purity Te was used as solvent for THM growth.

$\square$ Although BM technique is being used for crystal growth, our main thrust is THM growth of CZTS for its following advantages:

- Low-temperature growth

- Less chance of incorporation of impurities from the crucible during growth

- Less/no chance of ampoule explosion

- Enhanced purity of the ingot

- Fewer defects due to the lower growth temperature

$\checkmark$ Crystals were cut and polished for various characterizations and detector fabrication and testing. 


\section{Optimizing THM-growth parameters}

THM growth is highly sensitive to growth parameters.

i. Width of Te-rich solution zone

ii. Growth temperature

iii. Temperature gradient near the growth interface
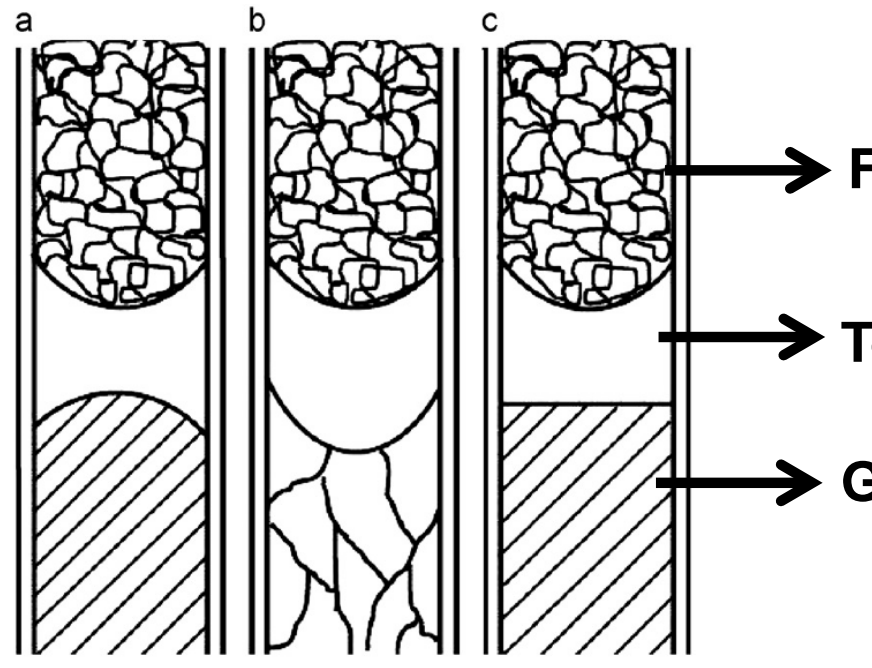

Schematic of growth interface shape growth of large grain and single

A) convex, B) concave and C) flat. crystalline ingots.

Convex and flat growth

interfaces are favorable for

Te-rich CZTS molten zone

Grown ingot 


\section{CZTS ingots}

$\square$ We are focusing on THM-growth of 2-in diameter CZTS ingots with different elemental compositions:

$\mathrm{Cd}_{0.9} \mathrm{Zn}_{0.1} \mathrm{Te}_{0.93} \mathrm{Se}_{0.07}$ ingots:

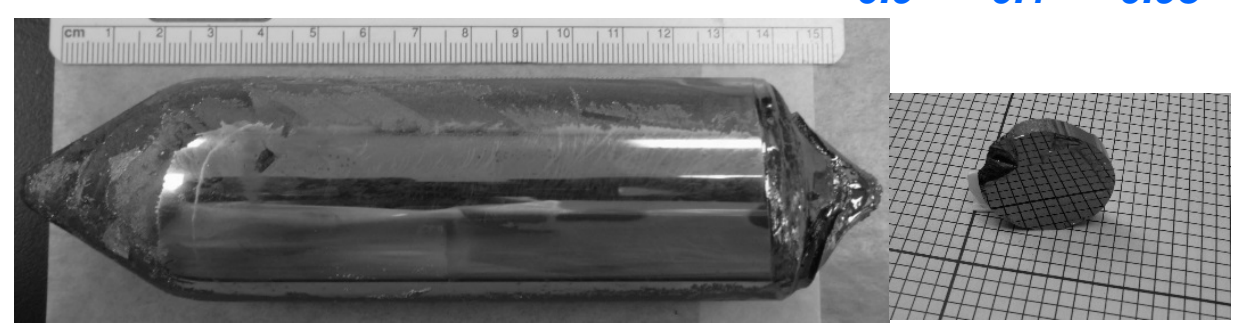

40-mm diameter ingot grown by BM (undoped).

$$
\mathrm{Cd}_{0.9} \mathrm{Zn}_{0.1} \mathrm{Te}_{0.96} \mathrm{Se}_{0.04}
$$

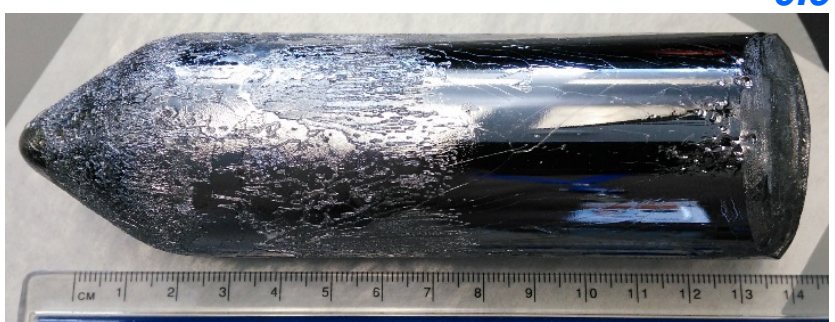

40-mm diameter ingot grown by BM (undoped).

$\mathrm{Cd}_{0.9} \mathrm{Zn}_{0.1} \mathrm{Te}_{0.98} \mathrm{Se}_{0.02}$ ingots:

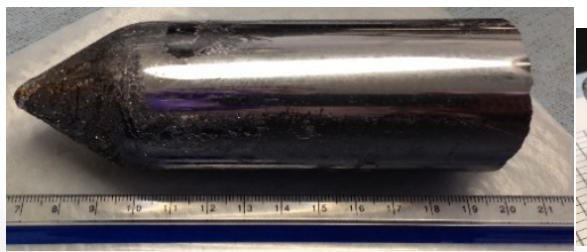

40-mm diameter ingot grown by BM (undoped).

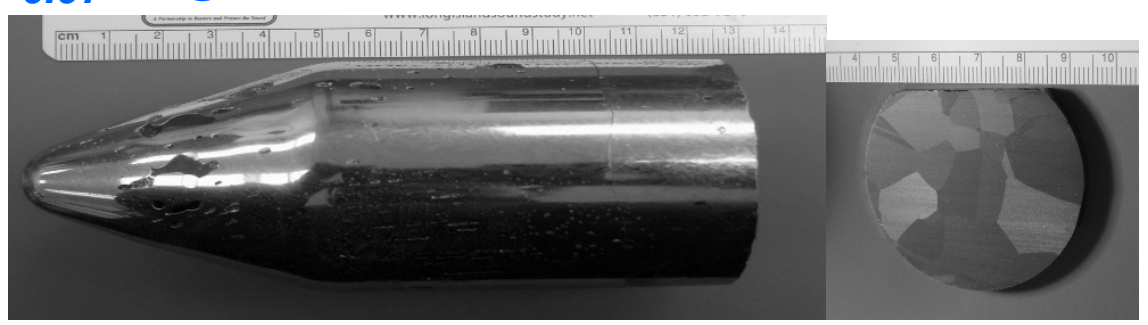

In-doped 52-mm diameter ingot grown by THM (fast cooled ingot).

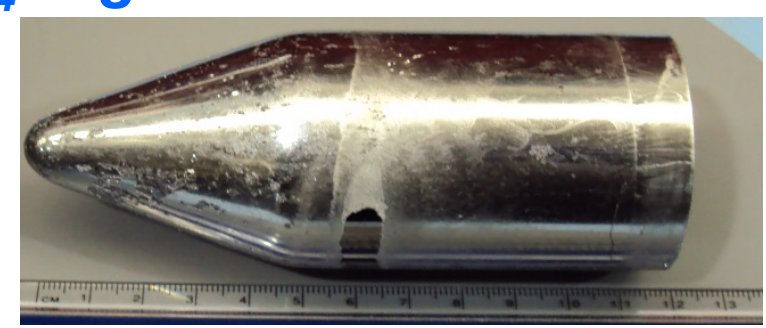

In-doped 52-mm diameter ingot grown by THM.

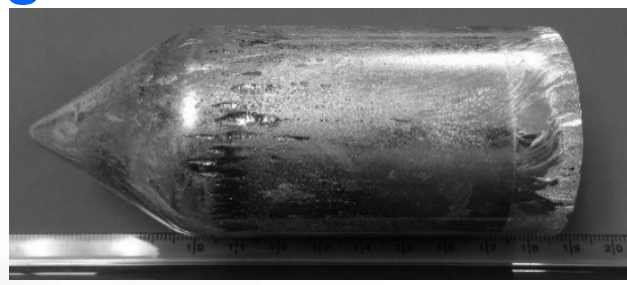

In-doped 52-mm diameter ingot grown RK THM F DISCOVERY 


\section{Combositional distributions in CZTS}
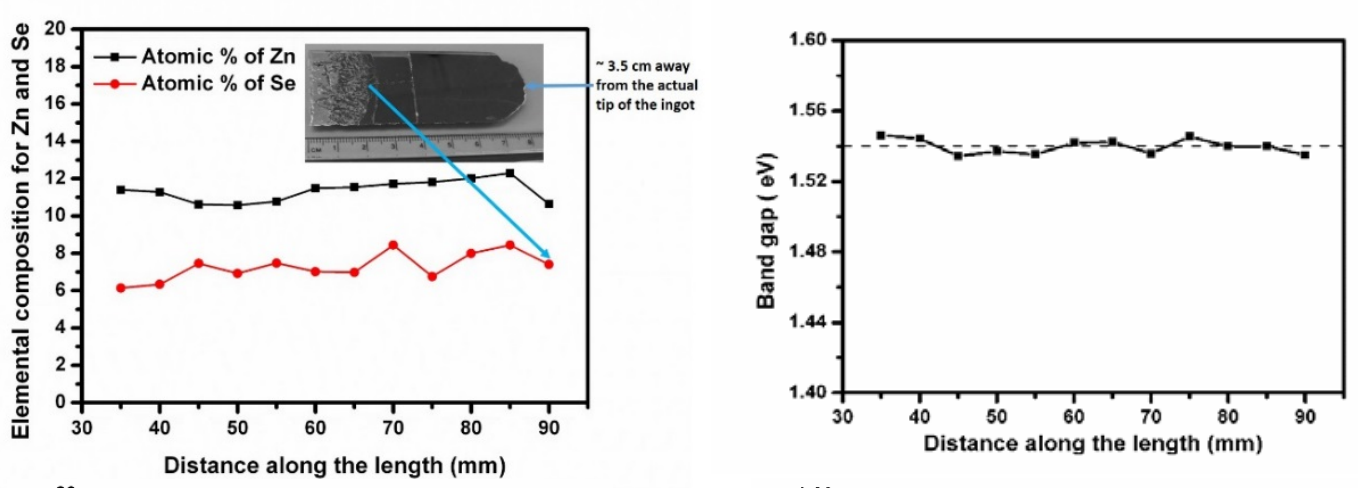

Composition of $\mathrm{Zn}$ and Se is fairly uniform throughout the ingot for $\mathrm{Cd}_{0.9} \mathrm{Zn}_{0.1} \mathrm{Te}_{0.93} \mathrm{Se}_{0.07}$. Especially the calculated band gap.

For $2 \%$ and $4 \%$ Se composition, the band gap of the ingots is

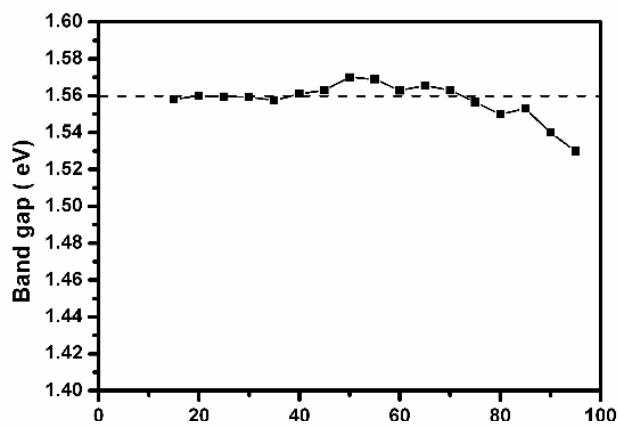
fairly uniform within the experimental accuracy. It only decreases in a narrow region ( $<1$ $\mathrm{cm})$ near the interface.

$\sim 90 \%$ of the ingot shows uniform band gap for both 2 and 4\% Se

Distance along the length $(\mathrm{mm})$
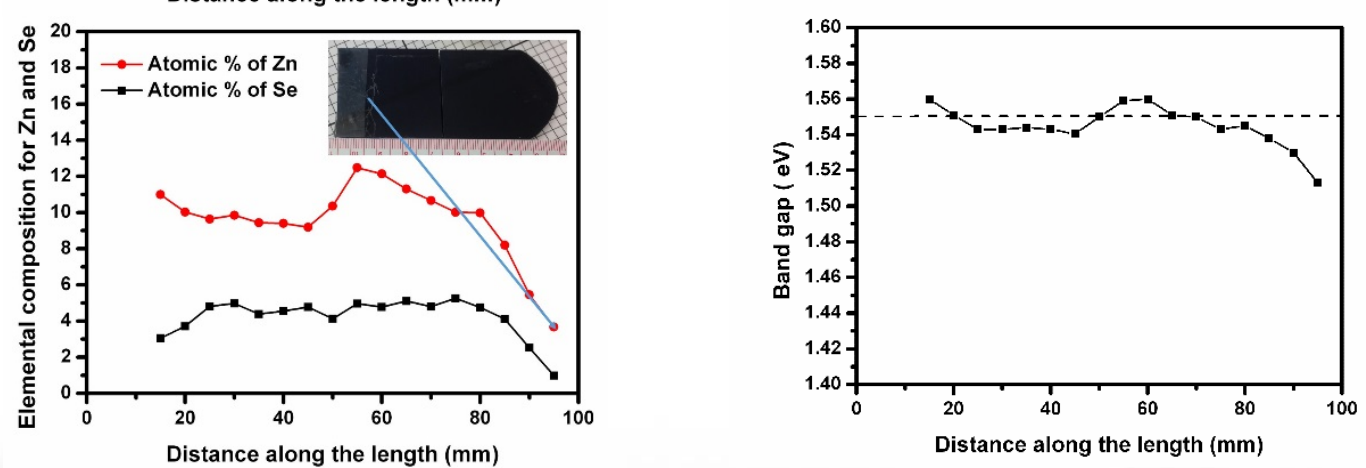
composition).

On the contrary, for THM grown CZT, only about one third of the ingot shows uniform composition.

$\mathrm{Zn}$ and Se composition and the calculated band gap along the length of the THM-grown $\mathrm{Cd}_{0.9} \mathrm{Zn}_{0.1} T e_{0.93} \mathrm{Se}_{0.07}, \mathrm{Cd}_{0.9} \mathrm{Zn}_{0.1} T e_{0.98} \mathrm{Se}_{0.02}$ and $\mathrm{Cd} d_{0.9} \mathrm{Zn_{0.1 }} T \mathrm{e}_{0.96} \mathrm{Se}_{0.04}$ ingots: from top to bottom. 


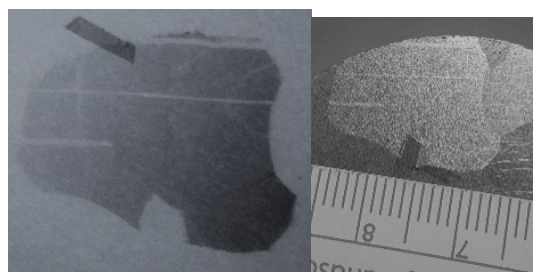

a

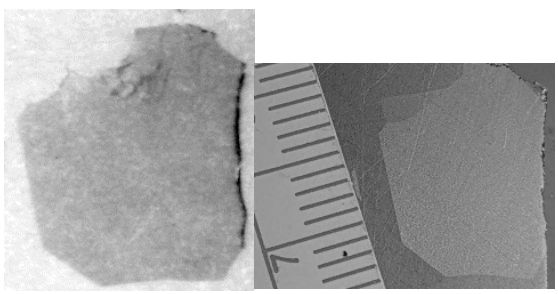

b

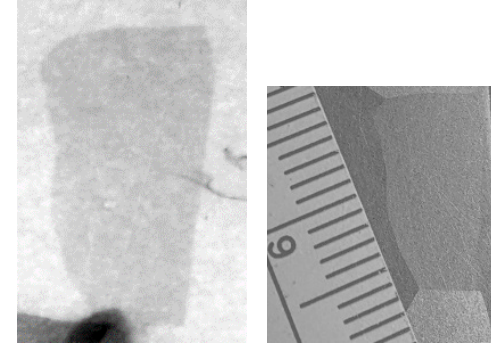

C

a)-c): X-ray topographic pictures of THM-grown $\mathrm{Cd}_{0.9} Z n_{0.1} T e_{0.93} S e_{0.07}$ sample and the corresponding optical photography of the grains.

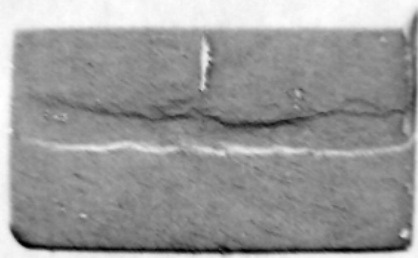

a

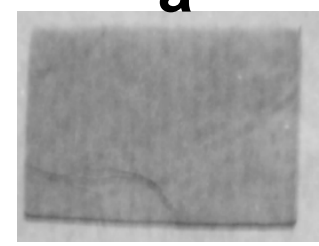

a

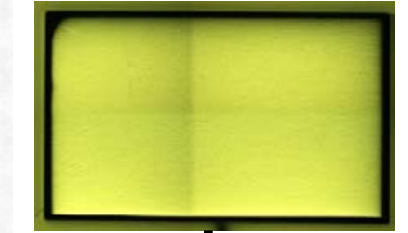

b

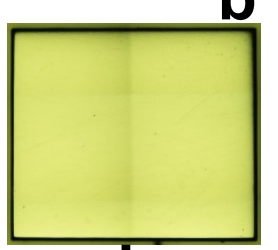

b

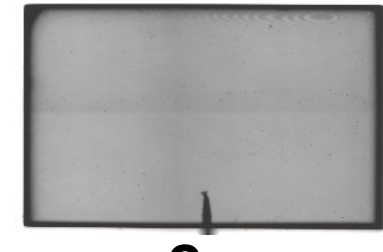

C

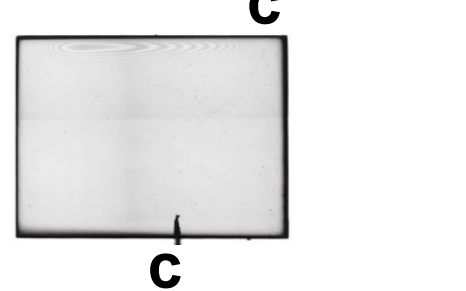

a) X-ray topographic, b) photograph of the polished sample in reflection mode and c) IR transmission picture of a THM-grown $\mathrm{Cd}_{0.9} \mathrm{Zn}_{0.1} \mathrm{Te}_{0.98} S \mathrm{e}_{0.02}$ sample. Dimensions: $8 \times 5.6 \times 2.5 \mathrm{~mm}^{3}$ and $8.2 \times 7 \times 1.55 \mathrm{~mm}^{3}$.

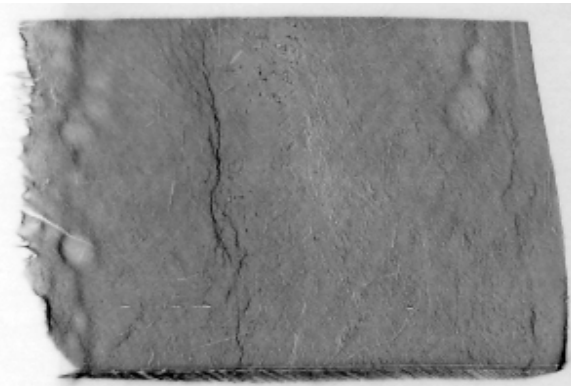

4

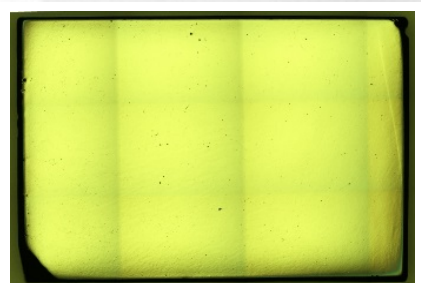

X-ray topographic picture and photograph of the polished sample. The surface area is $\sim 15 \times 10 \mathrm{~mm}^{2}$.

Higher Se concentration is more effective in arresting sub-grain boundary. No sub-grain boundary network was evidenced.

Sub-grain boundary network problem is alleviated for CZTS material. 


\section{Concentrations and size distribution of Te inclusions in CZTS}

For both Bridgman and THM grown $C d_{0.9} Z n_{0.1} T e_{0.93} S e_{0.07}$ ingots, concentrations of Te inclusions/precipitates were found 8-9 times lower than in standard CZT. 


\section{PL map of CZTS 2-inch wafer}
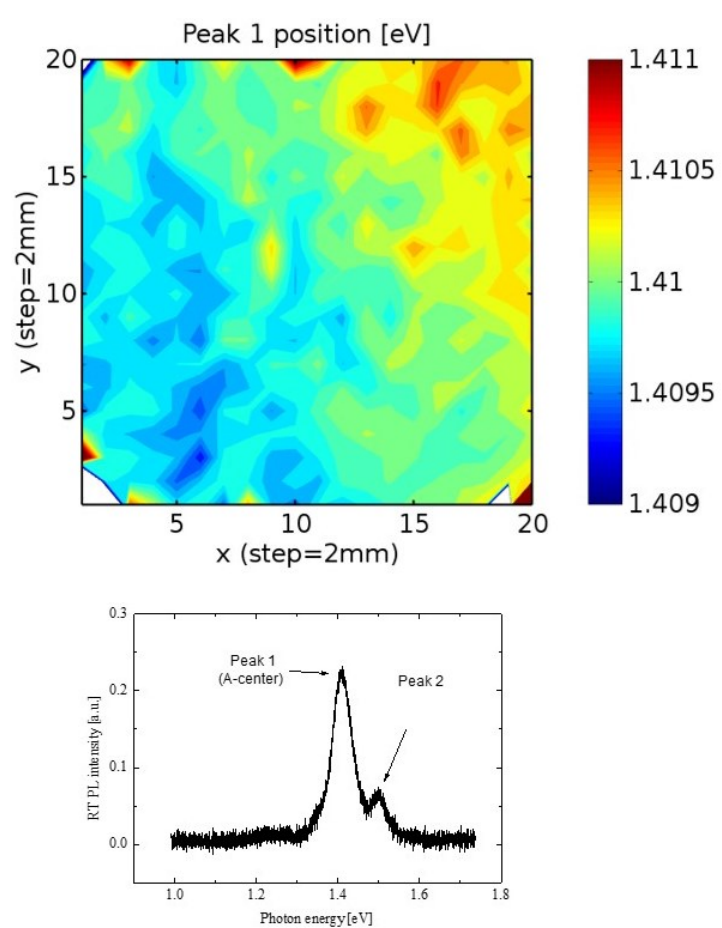

Room temperature photoluminescence ( $P L)$ map of $\mathrm{Cd}_{0.9} Z n_{0.1} \mathrm{Te}_{0.93} \mathrm{Se}_{0.07}$ two inch wafer grown by THM. The map area is $4 \times 4 \mathrm{~cm}^{2}$. Step size $2 \mathrm{~mm}$.

Variation of the peak energy (peak 1) over the entire scan area, $\Delta E$ is 2 meV, thus the composition and band gap are highly uniform over the $4 \times 4 \mathrm{~cm}^{2}$ area.

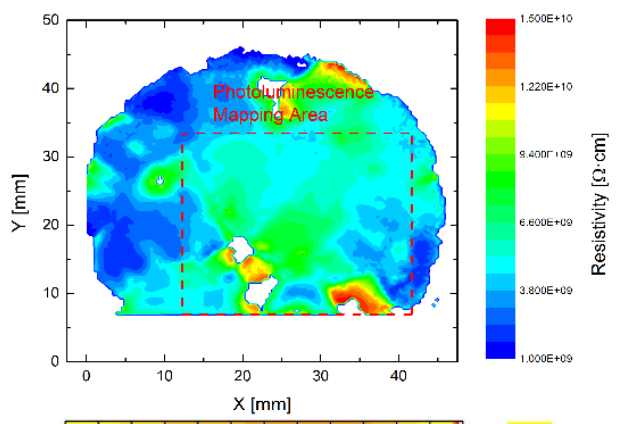

Composition and band gaps are highly uniform for both $2 \%$ and

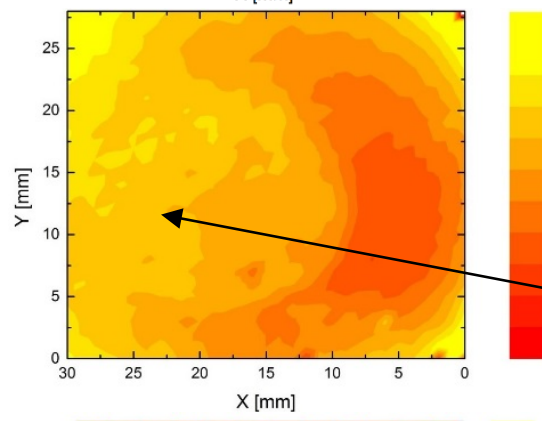
$7 \%$ Se containing CZTS wafers.
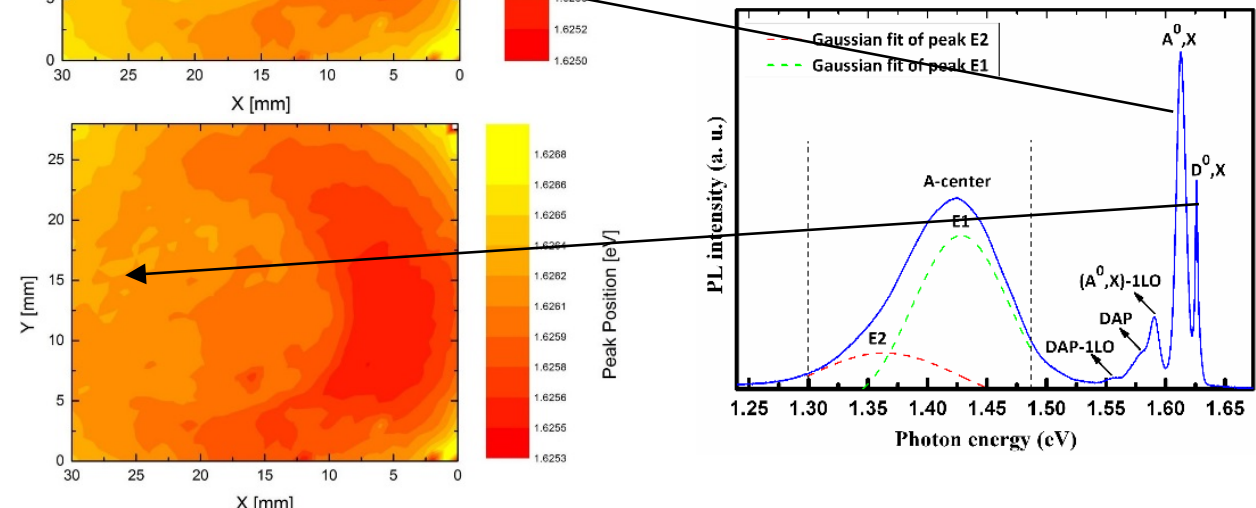

Low temperature (7K) photoluminescence $(P L)$ map of $C d_{0.9} Z n_{0.1} T e_{0.98} S e_{0.02}$ two inch wafer grown by THM. The map area is $\sim 2.8 \times 3 \mathrm{~cm}^{2}$. Step size $1 \mathrm{~mm}$.

Variation of the peak energy $\left(A^{0}, X\right.$ and $\left.D^{0}, X\right)$ over the entire scan area , $\Delta E$ is $\sim 1.5 \mathrm{meV}$, thus the composition and band gap are highly uniform over the $2.8 \times 3 \mathrm{~cm}^{2}$ area.

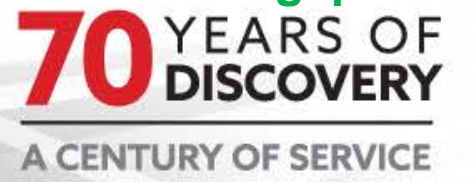




\section{Charge transport properties of THM- grown $\mathrm{Cd}_{0.9} \mathrm{Zn}_{0.1} T \mathrm{e}_{0.98} S \mathrm{e}_{0.02}$}

Charge collection versus applied bias voltage

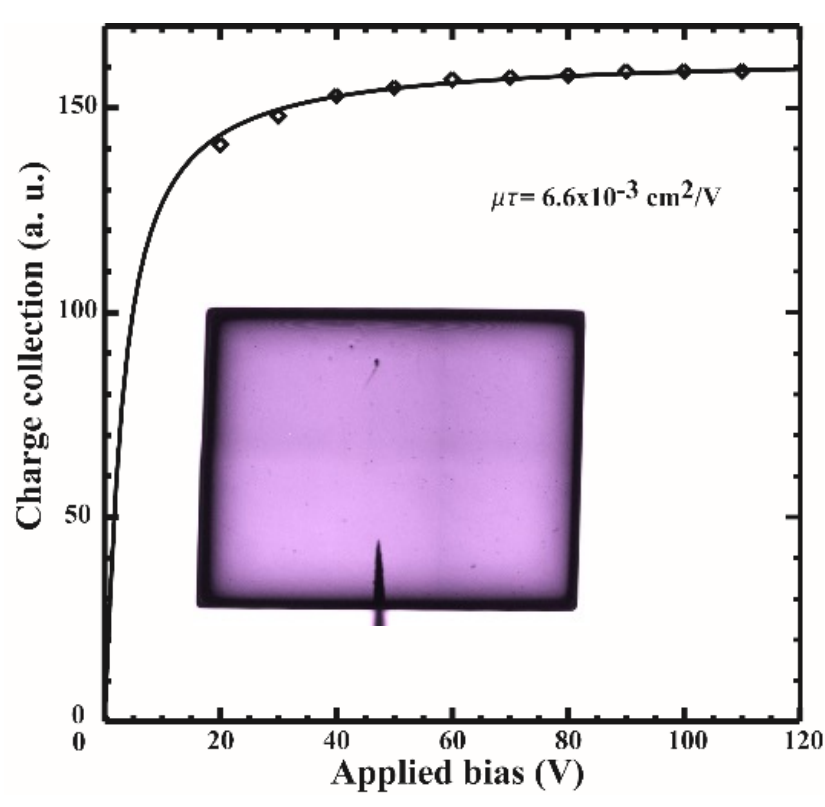

- ${ }^{241} \mathrm{Am}$ source

- Planar detector: $6.65 \times 5.75 \times 1.86 \mathrm{~mm}^{3}$

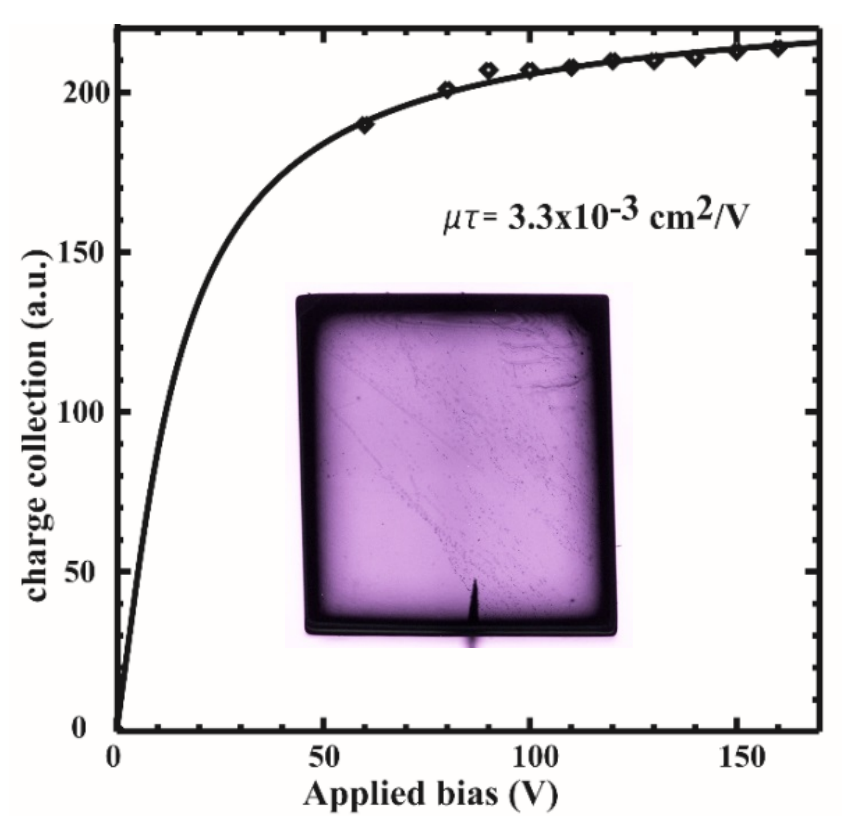

- ${ }^{241} \mathrm{Am}$ source

- Planar detector: $5.65 \times 5.18 \times 2.8 \mathrm{~mm}^{3}$

- Sample with more Te-inclusions/precipitations In general the $\mu \mathrm{r}$ product varies between $4.5-6 \times 10^{-3} \mathrm{~cm}^{2} / \mathrm{V}$. 


\section{$C d_{0.9} Z n_{0.1} T e_{0.98} S e_{0.02}$}
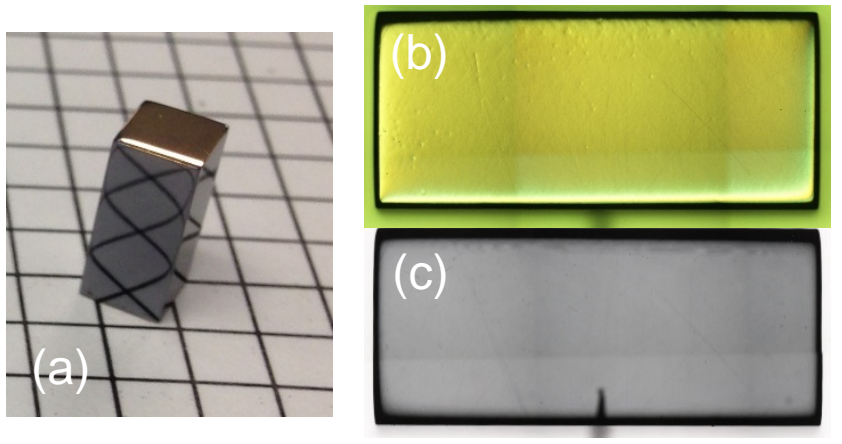

(a) Picture of the detector: $4.4 \times 4.4 \times 10 \mathrm{~mm}^{3}$

(b) Reflection mode microscopic scan

(c) IR transmission image

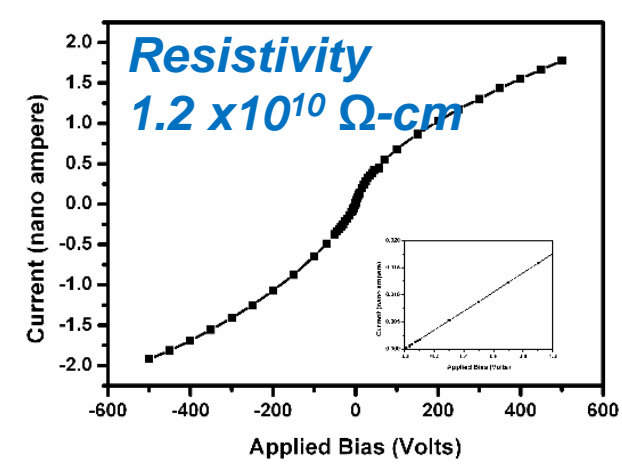

I-V characteristics at room temperature. Inset: I-V for 0-1V.

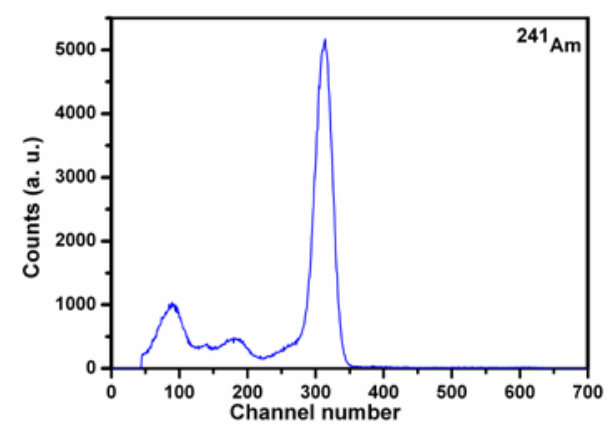

Bias voltage: $1800 \mathrm{~V}$

Shaping time 3 micro sec.
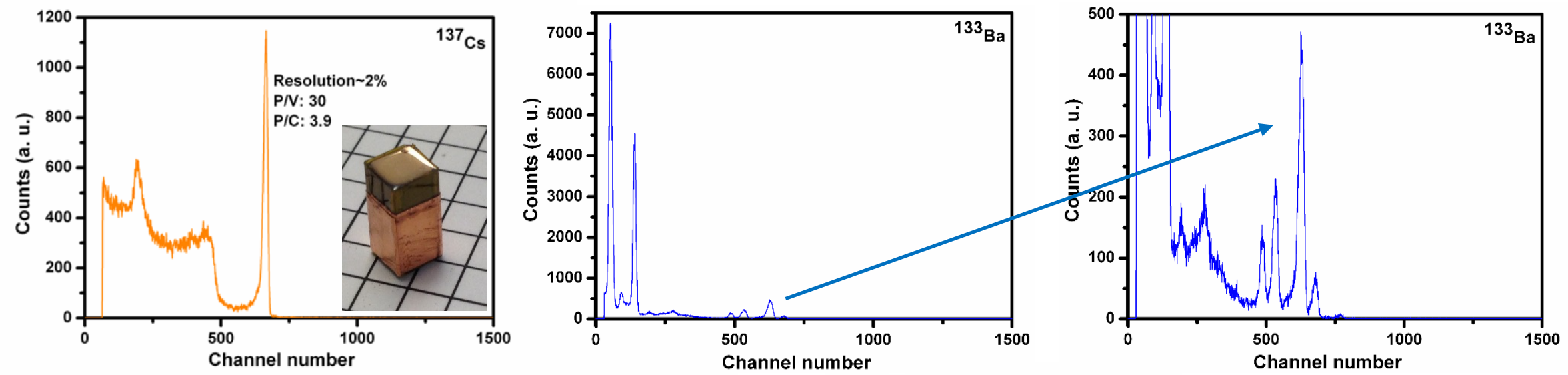

Bias voltage: $2300 \mathrm{~V}$, (Frisch grid $7 \mathrm{~mm}$ long) Shaping time $10 \mu \mathrm{s}$.

Bias voltage: 2300V, Shaping time $6 \mu \mathrm{s}$. All the spectra are as-measured without any correction technique. 0 YEARS OF (2) UENERGY 
Detector response of THM-grown $\mathrm{Cd}_{0.9} Z \mathrm{n}_{0.1} \mathrm{Te}_{0.98} \mathrm{Se}_{0.02}$
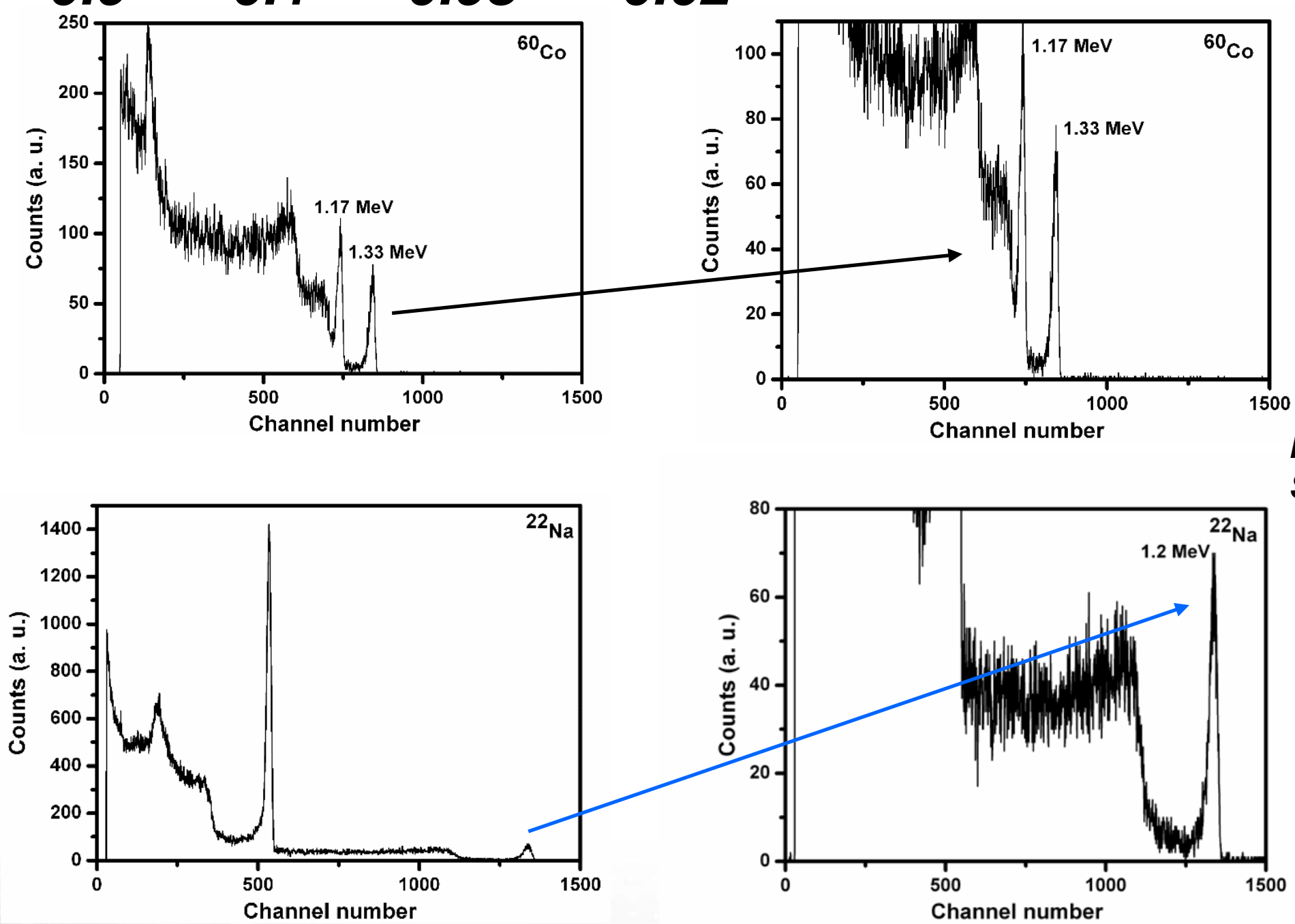

All the spectra are as-measured without any correction technique.

HV: -2300V,

Shaping time $10 \mu \mathrm{s}$ 


\section{CZTS virtual Frisch-grid detector}

Device response of another virtual Frisch grid detector.
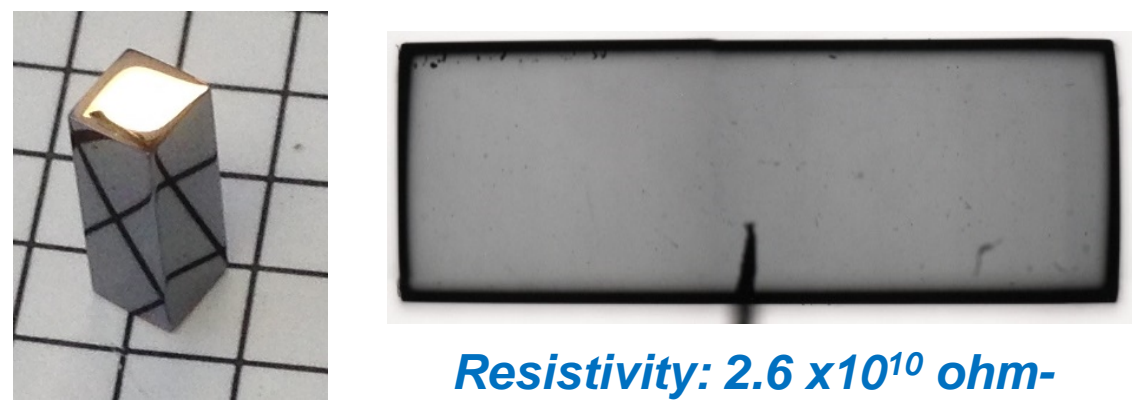

Resistivity: $2.6 \times 10^{10} \mathrm{ohm}-$

Left: Picture of the defector: $3.6 \times 3.4 \times 9.7 \mathrm{~mm}^{3}$ Right: microscopic scan IR transmission image

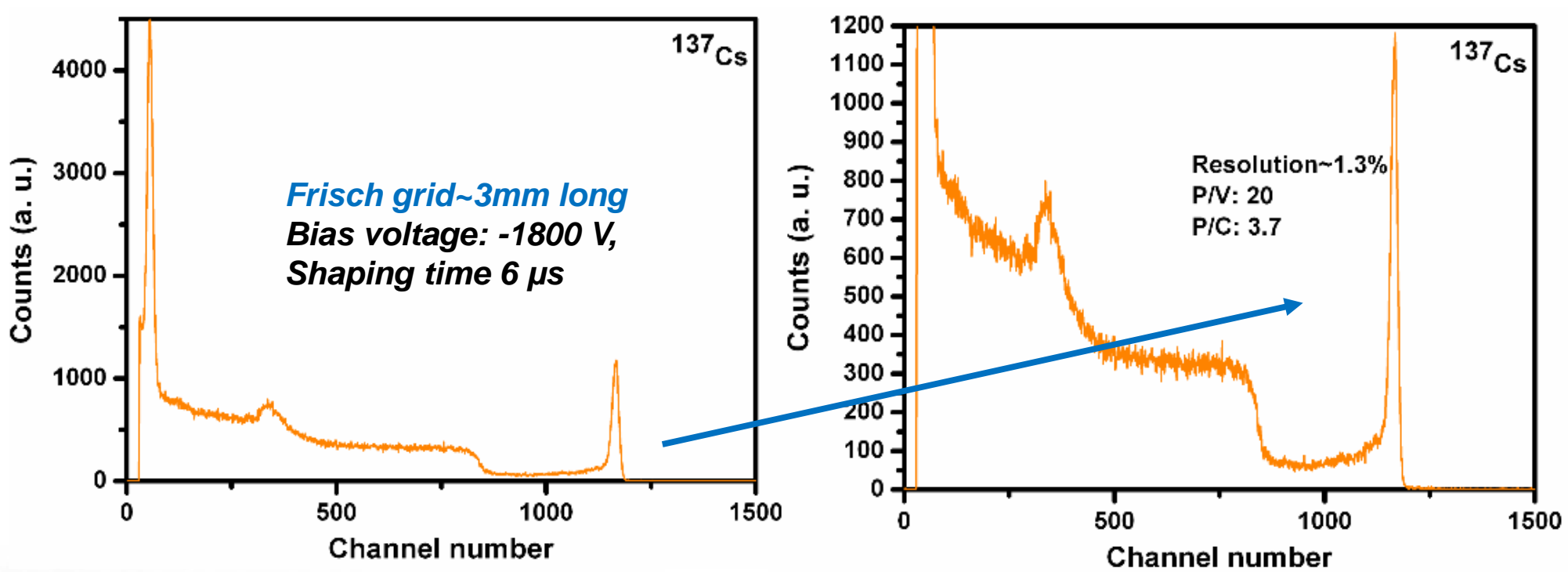

Bias voltage: 1800V, Shaping time 6 micro sec (Frisch grid $3 \mathrm{~mm}$ long) All the spectra are as-measured without any correction technique. 


\section{CZTS virtual Frisch-grid detector}

\section{Device response of anothervirtual Frisch grid detector.}
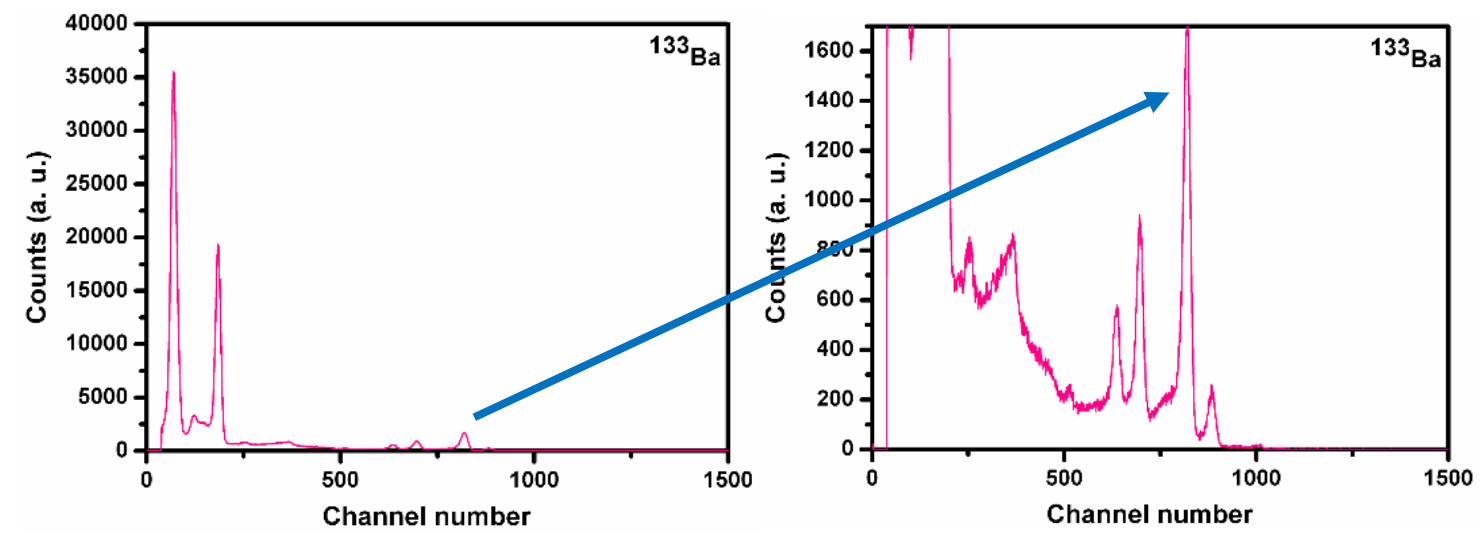

Bias voltage: 1800V, Shaping time 3 micro
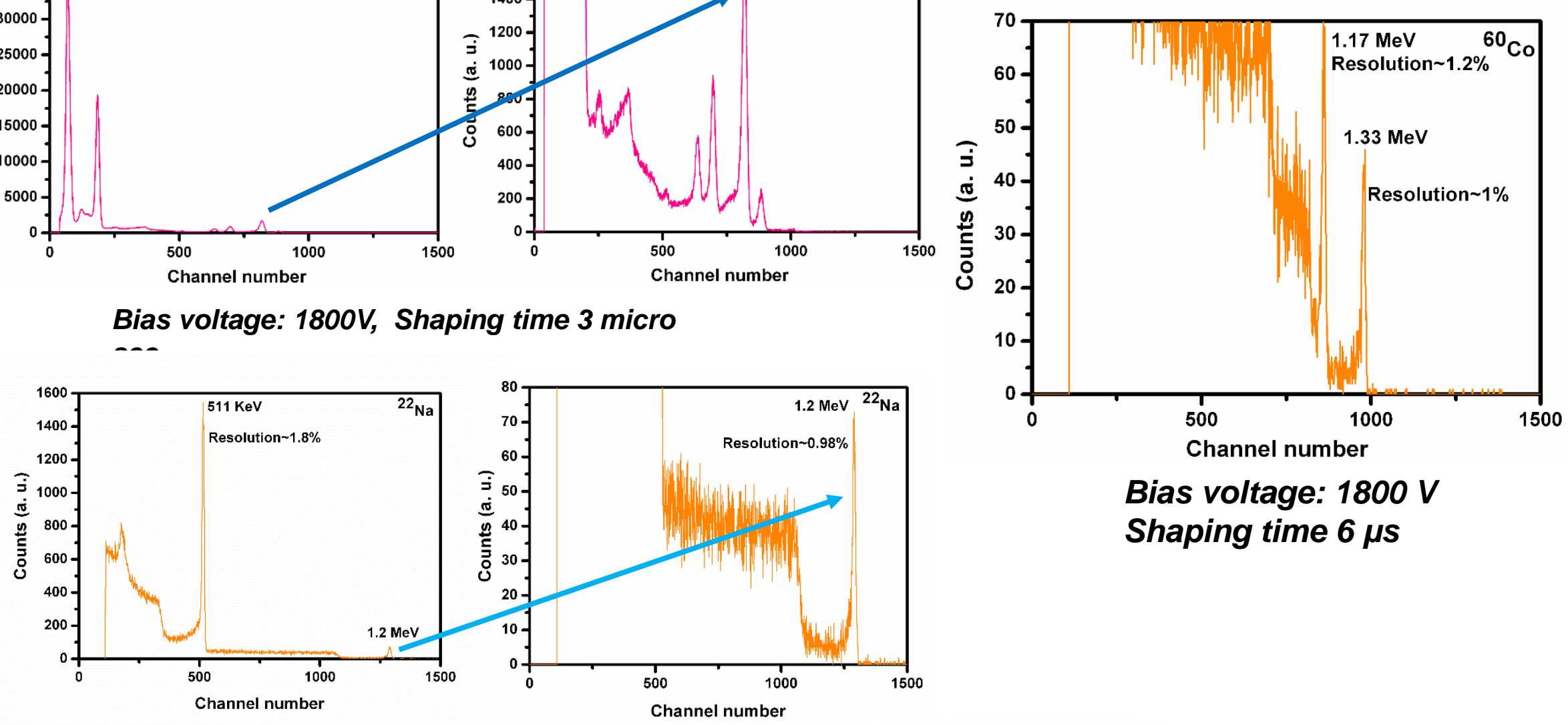

Bias voltage: $1800 \mathrm{~V}$, Shaping time $6 \mu \mathrm{s}$ All the spectra are as-measured without any correction technique. 


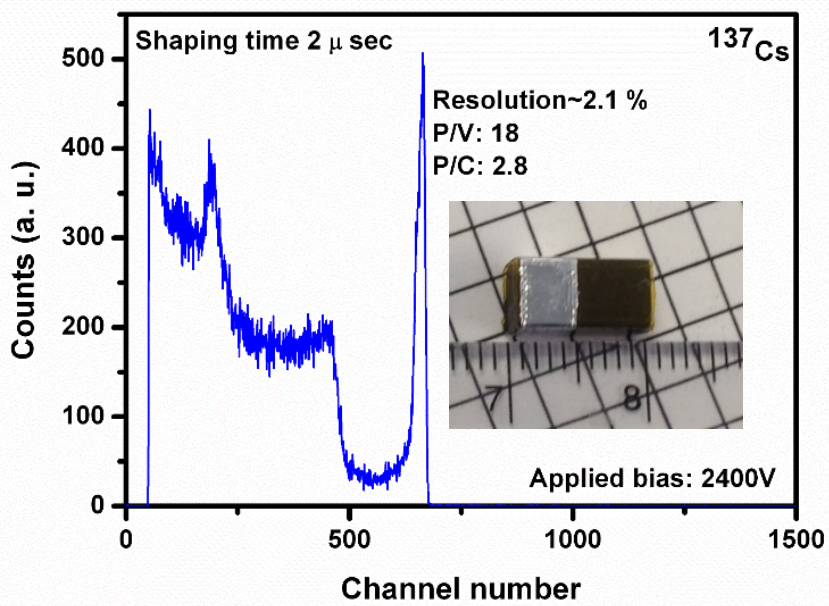

a

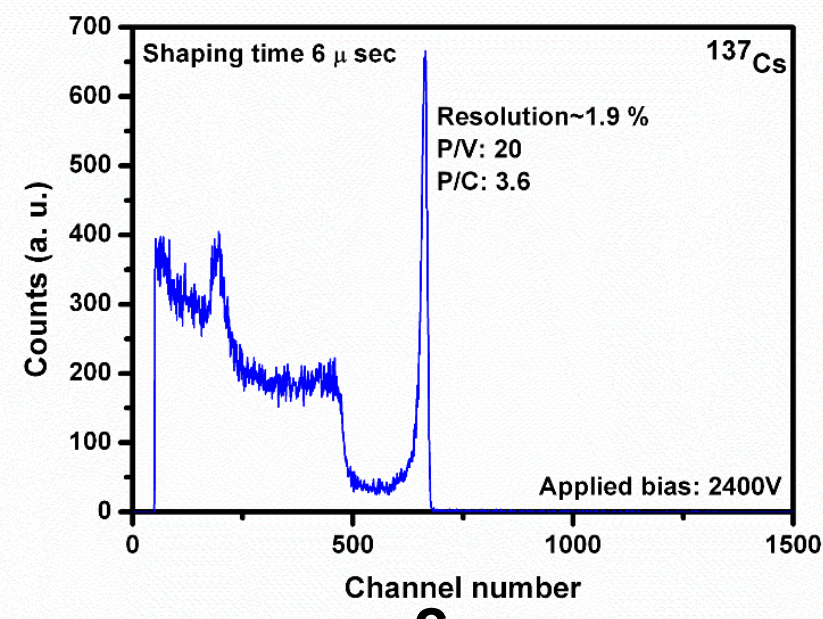

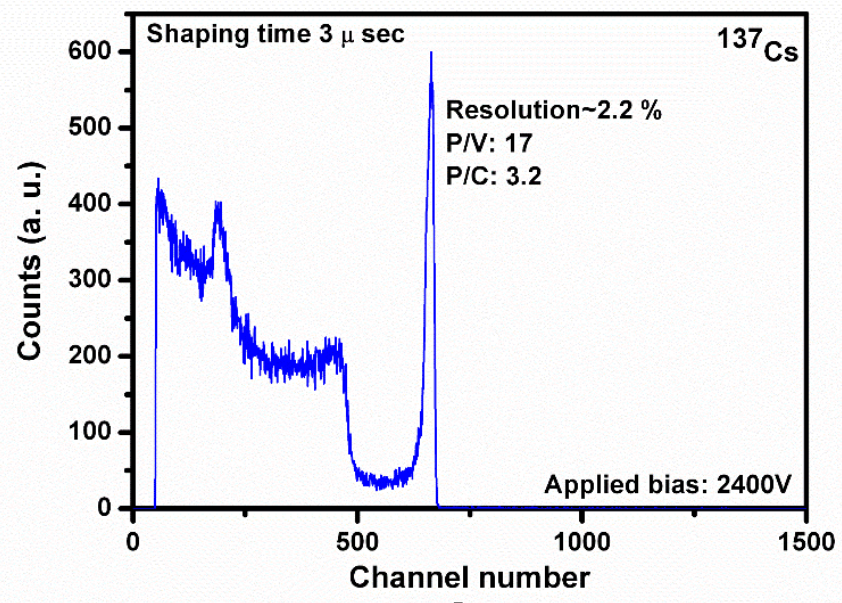

b

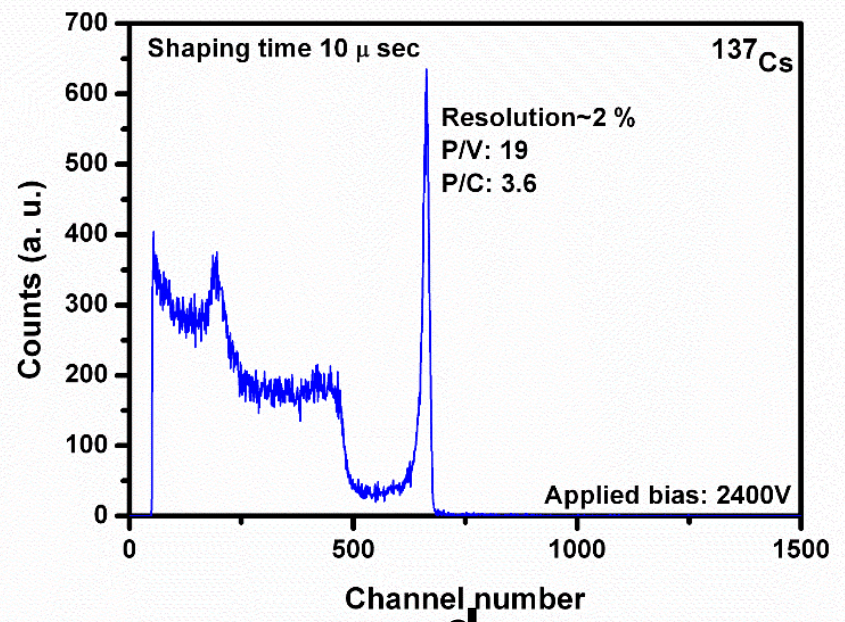

Response of VFG detector at different shaping time a) $2 \mu \mathrm{sec}, b) 3 \mu \mathrm{sec}, \mathrm{c}) \mathbf{8} \mu \mathrm{sec}$ and d) $10 \bar{\mu}$ sec. The detector dimensions: $4.8 \times 4.9 \times 97 \mathrm{~mm}^{3}$. (Frisch grid $4 \mathrm{~mm}$ long)

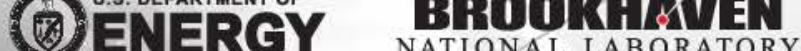


Detector response of THM-grown $C d_{0.9} Z n_{0.1} T e_{0.98} S e_{0.02}$ under different bias voltage
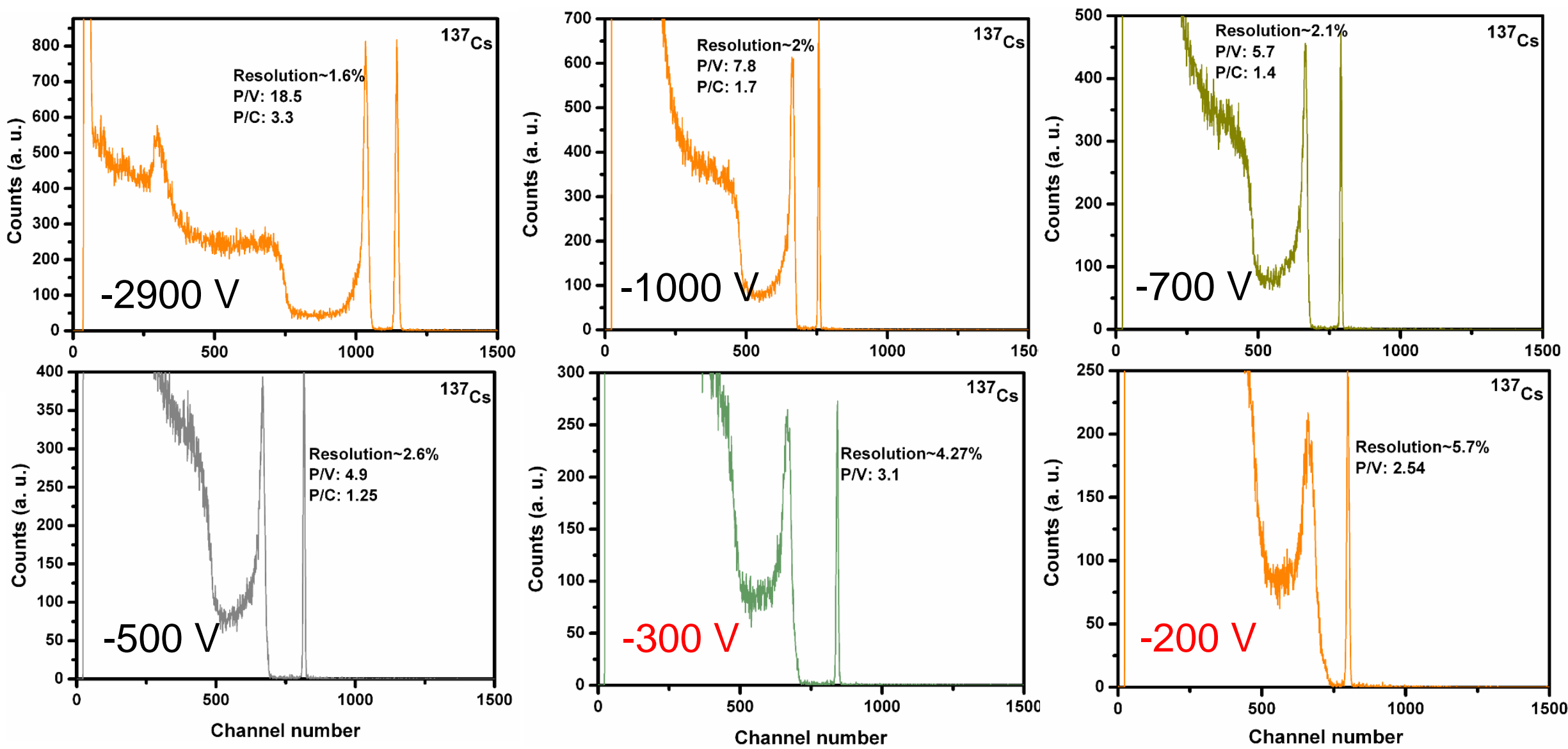

The detector dimensions: $3.4 \times 3.4 \times 9.15 \mathrm{~mm}^{3}$. (Frisch grid $3 \mathrm{~mm}$ long)

In spite of moderate $\mu$ T value, the device is operating even at low voltages. 


\section{Detector quality at a glance}

\begin{tabular}{|c|c|}
\hline IR image & IR image \\
\hline $\begin{array}{ll}\text { Dimensions: } 4.4 \times 4.4 \times 10 \mathrm{~mm}^{3} \\
\text { I at 500V }: 1.77 \mathrm{nA} \\
\text { Resistivity } & : 1.2 \times 10^{10} \mathrm{ohm}-\mathrm{cm} \\
\text { Resolution } & \\
\text { at } 662 \mathrm{keV} & : \sim 2 \% \\
\text { FG length } & : 7 \mathrm{~mm} \\
\end{array}$ & $\begin{array}{ll}\text { Dimensions: } 3.4 \times 3.4 \times 9.15 \mathrm{~mm}^{3} \\
\text { I at 500V }: 0.57 \mathrm{nA} \\
\text { Resistivity }: 1.5 \times 10^{10} \mathrm{ohm}-\mathrm{cm} \\
\text { Resolution } \\
\text { at } 662 \mathrm{keV}:=1.6 \% \\
\text { FG length }: 3 \mathrm{~mm} \\
\end{array}$ \\
\hline IR image & IR image \\
\hline Dimensions: $3.4 \times 3.6 \times 9.7 \mathrm{~mm}^{3}$ & Dimensions: $4.8 \times 4.9 \times 9.7 \mathrm{~mm}^{3}$ \\
\hline I at $500 \mathrm{~V} \quad: 0.77 \mathrm{nA}$ & I at $500 \mathrm{~V} \quad: 1.26 \mathrm{nA}$ \\
\hline $\begin{array}{l}\text { Resistivity : } 2.6 \times 10^{10} \mathrm{ohm}-\mathrm{cm} \\
\text { Resolution }\end{array}$ & $\begin{array}{l}\text { Resistivity : } 3 \times 10^{10} \text { ohm-cm } \\
\text { Resolution }\end{array}$ \\
\hline at $662 \mathrm{keV}:-1.3 \%$ & at $662 \mathrm{keV}:-1.9 \%$ \\
\hline FG length $\quad: 3 \mathrm{~mm}$ & FG length $\quad: 4 \mathrm{~mm}$ \\
\hline
\end{tabular}

Detector qualities are comparable to good quality CZT available today.

All the charge transport characteristics and the detector responses are performed on as-grown THM CZTS ingots. 


\section{Advantages of CZTS}

- Se was found to be very effective in:

i) arresting the sub-grain boundaries

ii) better compositional homogeneity and

iii) lowering the concentration of secondary phase

- High $\mu \mathrm{t}$ value was obtained with required resistivity.

- CZTS looks promising and has potential to supersede presently available CZT in terms of quality and yield at lower cost of production. 


\section{Example 1: ProxiScan ${ }^{\mathrm{TM}}$ Gamma Camera}

- ProxiScan ${ }^{\mathrm{TM}}$ : A compact digital gamma camera capable of insertion into the rectum as a probe, bringing the detectors directly adjacent to the prostate gland for high-resolution localization and imaging of prostate cancer.

- FDA 510(k) granted and clinical trials were done.

- Commercialization by industrial partner.

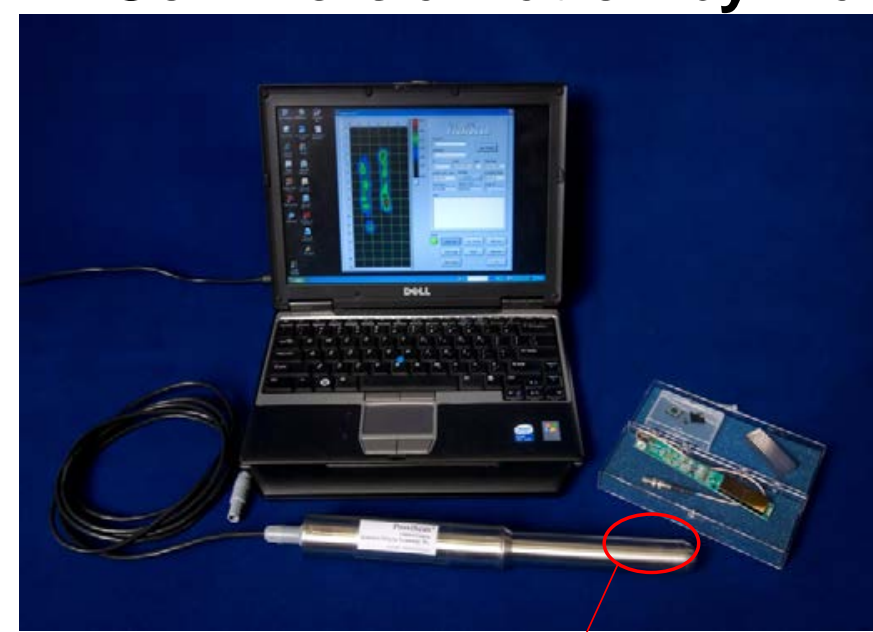

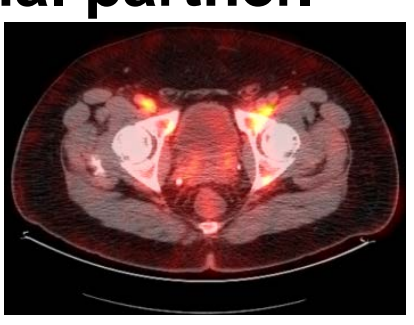

Transaxial view of mid-base region

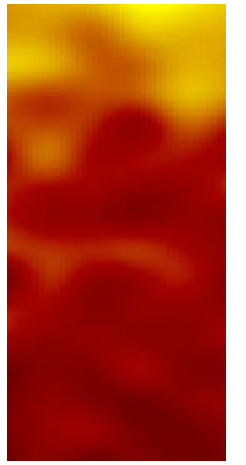

Right Base-mid

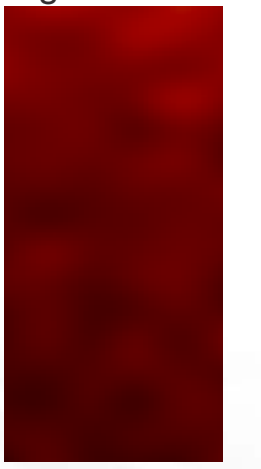

Right Apex

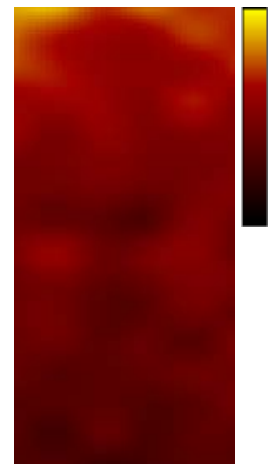

Left Base-mid

CZT detectors 


\section{Example 2: SPECT Imaging}

- $\quad$ CZTICZTS is also good for whole-body SPECT imaging

- Better image contrast

- Higher spatial resolution

- Higher efficiency

- Enabling energy-resolved photon counting

- We are working on a new SPECT detector head for energy-independent SPECT imaging

- 1.6-mm pixel CZT detector

- New ASIC for signal readout

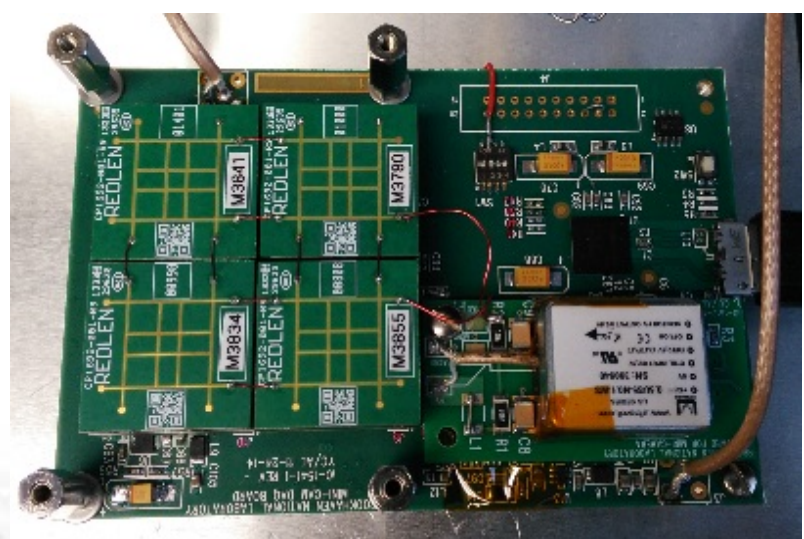

Prototype of SPECT detector head
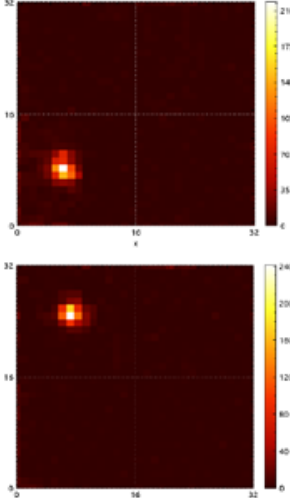

Co-57 images

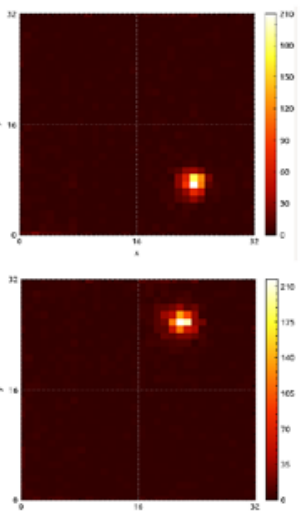

70 YEARS OF DISCOVERY 


\section{Summary}

$\square$ We successfully developed CZTS - a new promising material for radiation detection to replace $\mathrm{CdZnTe}$

- High homogeneity

- Less defects

- Low cost

- Comparable detector performance

$\square$ CZTS can be used in future equipment for medical imaging and nuclear detector applications

$\square$ BNL has unique R\&D expertise in room-temperature semiconductor detectors and their broad-range applications

- Material research

- Circuit development

- Instrument construction

$\square$ We welcome any collaboration on medical imaging and related technologies 


\section{Acknowledgement}

This work was supported by the U.S. Department of Energy, Defense Nuclear Nonproliferation R\&D.

Thank you for your kind attention! 